\title{
The Indiscriminate Use of Supplements
}

\section{Elisa C Gomes*}

Edinburgh Napier University, United Kingdom

Antioxidants are important against Reactive Oxygen Species (ROS) and free radicals. The latter, when present in high concentration can lead to oxidative stress: cause and consequence of many diseases [1]. It is common sense that reactive species are always detrimental to our organism; however, this is not true. In fact, they are essential not only to the correct functioning of our body but also to our well-being: through gene stimulation, cell signaling processes, vasoregulation and respiratory burst, just to mention a few [2,3]. Nevertheless, the harmful effects of the reactive species are a simplified notion persistent in our society. This has led people to supplement their diets with multivitamins and minerals in an attempt to ingest larger amount of antioxidants to balance out the negative effect of such radicals.

It is estimated that approximately 219 million people in the USA (70\% of the population), at least occasionally, make use of dietary supplements. In the UK, it is estimated that approximately $£ 326$ million (528 million dollars) was spent in stores in the purchase of vitamin and minerals (not including internet sales) in 1999 [4,5]. It is interesting to point out that these data are from developed countries where the population that has money to buy vitamin supplementation also has money to buy good quality food potentially containing the recommended daily allowance of vitamin and minerals. The need for vitamin supplement intake concomitant to a well-balanced diet is in effect still controversial. The chronic use of some supplements has indeed been shown to have a negative effect, e.g. vitamin $\mathrm{E}$ has been associated with an increase in mortality [6]. Therefore, although certain supplements have been thoroughly researched and have known beneficial effects, healthy individuals should take them with caution (results concerning synthetic antioxidants should not be transferred to effects that fruit and vegetables have on human health).

In the context of Sport Science, this matter is also of relevance, with individuals having an extra reason to make use of such supplements: it has been well established that muscle contraction, especially when intense and during a prolonged period, increases the production and release of ROS and free radicals $[7,8]$. In low concentration, the radicals in the muscles play an important signaling role for its contractile function. Such radicals are essential for force generation and for exercise adaptation. Nonetheless, as the radicals start accumulating in the contracting muscles, the oxidation of proteins and lipids might cause - amongst other problems - contractile dysfunction leading to inhibition in force production and contributing to the development of acute fatigue [9]. Whether that would justify the supplementation of antioxidant vitamins by exercising individuals or even athletes in order to improve performance and attenuate oxidative stress is, thus, a significant matter. However, although there is a need for more studies analyzing benefits, optimal dosage strategy and combination of antioxidant supplementation for competitive and active individuals; so far there is little evidence to recommend vitamin intake for performance enhancement.

Moreover, the presence of reactive species in the muscles during exercise is essential not only for exercise adaptation and improvement, but also for an increase in the body's endogenous antioxidant concentration. Researchers have shown that exercise training leads to an adaptive up regulation of antioxidant status as it stimulates the antioxidant enzyme activity of various tissues, including muscle, brain and liver; besides also enhancing other oxidative stress protection pathways [10-15]. In fact, chronic use of antioxidant supplementation can actually have a negative effect on the adaptation to exercise training $[14,16]$.

Sport Scientists, trainers and coaches need to have more information on this topic to be able to explain to exercise practitioners and athletes the importance of a balanced diet and the pros and cons of using any supplement. Vitamins and antioxidants have been the main focus here, but there is a growing range of commercially available supplements which also need to go under scrutiny. Because even with little scientific evidence supplements are enticing to individuals that want to be healthier, or perform better or look nicer. There is a growing requirement for more research looking into the benefits and side-effects of supplements in different sporting scenarios, including extreme environmental condition. In addition, results of well conducted studies have to be made more readily available and disseminated to the public.

\section{References}

1. Halliwell B, Gutteridge JMC (2007) Free Radicals in Biology and Medicine. (3rdedn), Oxford University Press, New York.

2. Kuby J (1997) Immunology. (3rdedn), W.H. Freeman and Company, New York.

3. Sen CK (2001) Antioxidant and redox regulation of cellular signaling: introduction. Med Sci Sports Exerc 33: 368-370.

4. Hathcock JN, Azzi A, Blumberg J, Bray T, Dickinson A, et al. (2005) Vitamins $\mathrm{E}$ and $\mathrm{C}$ are safe across a broad range of intakes. Am J Clin Nutr 81: 736-745.

5. Expert Group on Vitamins and Minerals (2003) Safe Upper Levels for Vitamins and Mineral.

6. Bjelakovic G, Nikolova D, Gluud LL, Simonetti RG, Gluud C (2007) Mortality in Randomized Trials of Antioxidant Supplements for Primary and Secondary Prevention: Systematic Review and Meta-analysis. JAMA 297: 842-857.

7. Powers SK, Ji LL, Leewenburgh C (1999) Exercise training induced alterations in skeletal muscle antioxidant capacity: a brief review. Med Sci Sports Exerc 31: 987-997.

8. Sen CK, Roy S (2001) Antioxidant regulation of cell adhesion. Med Sci Sports Exerc 33: 377-381.

9. Reid MB (2001) Nitric oxide, reactive oxygen species, and skeletal muscle contraction. Med Sci Sports Exerc 33: 371-376.

10. Kanter M (1998) Free radicals, exercise and antioxidant supplementation. Proc Nutr Soc 57: 9-13.

11. Wilson DO, Johnson $P$ (2000) Exercise modulates antioxidant enzyme gene expression in rat myocardium and liver. J Appl Physiol 88: 1791-1796.

12. Radak Z (2000) Free Radicals in Exercise and Aging. Champaign, IL, Human Kinetics.

*Corresponding author: Senthil P Kumar, Maharishi Markandeshwar Institute of Physiotherapy and Rehabilitation (MMIPR), Maharishi Markandeshwar University (MMU), Mullana (Ambala), India, Tel: 00919341963889; E-mail: senthil.p.kumar@mmumullana.org

Received November 25, 2013; Accepted November 26, 2013; Published November 30, 2013

Citation: Gomes EC (2013) The Indiscriminate Use of Supplements. J Sports Med Doping Stud 3: e139. doi:10.4172/2161-0673.1000e139

Copyright: (c) 2013 Gomes EC. This is an open-access article distributed under the terms of the Creative Commons Attribution License, which permits unrestricted use, distribution, and reproduction in any medium, provided the original author and source are credited. 
13. Gomez-Cabrera M, Domenech E, Vina J (2008) Moderate-exercise is an antioxidant: upregulation of antioxidant genes by training. Free Radic Biol Med 44: $126-131$

14. Gomez-Cabrera M, Domenech E, Romagnoli M, Arduini A, Borras C, et al. (2008) Oral administration of vitamin $C$ decreases muscle mitochondrial biogenesis and hampers training-induced adaptations in endurance performance. Am J Clin Nutr 87: 142-149.
15. Radak Z, Chung HY, Goto S (2008) Systemic adaptation to oxidative challenge induced by regular exercise. Free Radic Biol Med 44: 153-159.

16. Gomez-Cabrera M, Borras C, Pallardo FV, Sastre J, Ji LL, et al. (2005) Decreasing xanthine oxidase-mediated oxidative stress prevents useful cellular adaptations to exercise in rats. J Physiol 567: 113-120. 